\title{
REVISIONES
}

\section{Enfermedades bacterianas de eucaliptos. Estado actual del conocimiento}

\author{
Bacterial diseases on eucalypts. Current knowledge
}

\author{
Cintia Palladino a, Guillermo Pérez ${ }^{\mathrm{b}}$, Carlos A Pérez ${ }^{\mathrm{c} *}$ \\ a Universidad de la República, Centro Universitario de Paysandú, \\ Polo de Desarrollo Universitario Abordaje Holístico: GEIA, Paysandú, Uruguay.

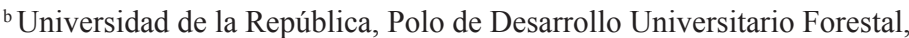 \\ Centro Universitario de Tacuarembó, Tacuarembó, Uruguay. \\ *Autor de correspondencia: ${ }^{c}$ Universidad de la República, Facultad de Agronomía, Departamento de Protección Vegetal, \\ EEMAC, Ruta 3 Km 363, Paysandú, Uruguay, tel.: +598-472-27950, caperez@fagro.edu.uy
}

\begin{abstract}
SUMMARY
In recent years there has been a substantial increase in health problems on Eucalyptus spp. plantations elsewhere. Several diseases are currently affecting this crop, predominantly those caused by fungi. However, bacterial diseases have globally increased in importance. Eucalyptus plant pathogenic bacteria can cause: i) leaf spots, ii) shoot blight and iii) vascular wilt. Bacterial leaf spots have been associated with genera Xanthomonas, Pseudomonas, Erwinia, Pantoea and Rhizobiaceae, being Xanthomonas axonopodis the predominant species. Bacterial die-back of bacterial shoot blight can be caused by several species, namely Erwinia psidii, Pantoea ananatis, Enterobacter cowanii, Xanthomonas campestris and X. vasicola, whereas vascular wilt has been associated with Ralstonia solanacearum and Erwinia psidii. These diseases represent a potential risk for forestry production, as reported in different climatic zones worldwide causing serious economic loss, in both nursery and field, affecting a wide host range in the genus Eucalyptus, and some species of Psidium. In addition, the effective dissemination of these bacterial diseases makes controlling them difficult, thus the deployment of genetic resistance germplasm is strongly recommended to minimize the impact of these diseases.
\end{abstract}

Key words: plant pathogenic bacteria, leaf spots, die-back, vascular wilt.

\section{RESUMEN}

En los últimos años se ha observado un aumento sustantivo de las problemáticas sanitarias en las plantaciones de Eucalyptus spp. (eucalipto) Diversas enfermedades afectan actualmente a este cultivo, predominando aquellas causadas por hongos. Sin embargo, las enfermedades de origen bacteriano han aumentado su importancia a nivel mundial. Las bacterias fitopatógenas en eucalipto pueden causar: i) manchas foliares, ii) tizón apical y iii) marchitamiento vascular. En el mundo, las manchas foliares bacterianas han sido asociadas a los géneros Xanthomonas, Pseudomonas, Erwinia, Pantoea y Rhizobiaceae, siendo Xanthomonas axonopodis la especie predominante. El tizón bacteriano puede ser causado por distintas especies bacterianas, Erwinia psidii, Pantoea ananatis, Enterobacter cowanii, Xanthomonas campestris y $X$. vasicola. Mientras que el marchitamiento vascular ha sido asociado a Ralstonia solanacearum y Erwinia psidii. Estas enfermedades representan un potencial riesgo para la producción forestal, ya que han sido reportadas en diversas zonas climáticas del mundo ocasionando graves pérdidas económicas, tanto en vivero como en campo, pudiendo afectar un amplio rango de hospederos dentro del género Eucalyptus, como también algunas especies del género Psidium. Sumado a esto, las bacterias se diseminan con facilidad dificultando su control, por lo que la principal medida de manejo es la utilización de germoplasma con mejor comportamiento sanitario.

Palabras clave: bacterias fitopatógenas, manchas foliares, tizón apical, marchitamiento vascular.

\section{INTRODUCCIÓN}

La superficie plantada con eucalipto (Eucalyptus spp.) ha ido en aumento a nivel mundial, superando actualmente los 20 millones de hectáreas (Naidoo et al. 2014). Sin embargo, pese a la exitosa producción forestal, en los últimos años, se ha observado un aumento de las problemáticas sanitarias. Diversas enfermedades afectan actualmente las plantaciones de eucalipto a nivel mundial, los principales agentes causales de enfermedades son y han sido los hongos, han predominado históricamente causando manchas foliares, cancro de fuste o ramas, muerte regresiva, marchitamiento vascular y roya (Pérez et al. 2010).

Sin embargo, en los últimos años la ocurrencia de agentes causales de origen bacterianos ha tomado relevancia, reportándose hasta el momento tres grupos de enfer- 
medades bacterianas asociadas a especies de Eucalyptus: i) manchas foliares, ii) tizón apical y iii) marchitamiento vascular. Estas enfermedades son relativamente recientes, cuya información disponible está dispersa y relacionada a los lugares en donde se reportó. Por ello, el objetivo del presente trabajo es reunir, sintetizar y describir el estado del conocimiento de este grupo de enfermedades a nivel mundial. Por esta razón, los capítulos de esta revisión corresponden a los tres grupos de enfermedades hasta el momento reportadas en el mundo.

\section{MANCHAS FOLIARES BACTERIANAS}

Etiología y sintomatología. Las manchas foliares causadas por bacterias en eucalipto fueron descriptas por primera vez en Cuba en el año 1983, cuando Querejeta et al. (1990), reportaron la ocurrencia de mancha bacteriana asociada a Xanthomonas spp. Los síntomas fueron descritos como manchas angulares de aspecto húmedo grasoso, de coloración parda, distribuidas por todo el limbo y/o concentrados a lo largo de la nervadura principal de la hoja (Querejeta et al. 1990).

Estudios posteriores han ampliado el conocimiento de los agentes causales de esta enfermedad y actualmente se registran más de una decena de especies bacterianas asociadas a manchas foliares en eucalipto (cuadro 1). En Brasil, las especies bacterianas asociadas a manchas foliares incluyen a Erwinia psidii Rodrigues Neto, Robbs et Yamashiro, Pseudomonas cichorii (Swingle) Stapp, Rhizobiaceae, y Xanthomonas axonopodis Starr et Garces, (Gonçalves et al. 2001, Gonçalves et al. 2008), siendo $X$. axonopodis la especie predominante en Brasil (Gonçalves et al. 2008). En Sudáfrica se asocia a Pantoea agglomerans (Beijerinck) Gavini et al. y Pantoea ananatis (Serra-

Cuadro 1. Rango de hospederos, etapa de producción, y país donde ha sido reportada cada especie bacteriana asociada a manchas foliares en Eucalyptus spp. has been reported.

Host range, production stage and country where each bacterial species associated with bacterial leaf spot in Eucalyptus spp.

\begin{tabular}{|c|c|c|c|c|}
\hline Agente causal & Hospedero & Etapa de producción & País & Referencias \\
\hline \multirow[t]{3}{*}{ Erwinia psidii } & E. dunnii & Campo y vivero & Argentina & Gonçalves et al. 2001 \\
\hline & E. grandis & & Brasil & \\
\hline & E. globulus & & & \\
\hline \multirow[t]{2}{*}{ Pantoea agglomerans } & E. grandis & Campo y vivero & Argentina & Gonçalves et al. 2001 \\
\hline & & & Brasil & \\
\hline \multirow[t]{3}{*}{ Pseudomonas cichorii } & E. grandis & Campo y vivero & Brasil & Pomella et al. 1995 \\
\hline & E. grandis $x$ E. urophylla & & & Gonçalves et al. 2008 \\
\hline & $\begin{array}{l}\text { E. urophylla } \times E \text {. } \\
\text { maidenii }\end{array}$ & & & \\
\hline \multirow[t]{2}{*}{ Rhizobiaceae } & E. grandis $x$ E. urophylla & Campo y vivero & Brasil & Gonçalves et al. 2008 \\
\hline & $\begin{array}{l}\text { E. urophylla } x E \text {. } \\
\text { maidenii }\end{array}$ & & & \\
\hline \multirow[t]{3}{*}{$X$. axonopodis } & E. grandis & Campo y vivero & Brasil & Gonçalves et al. 2008 \\
\hline & E. grandis $x$ E. urophylla & & & \\
\hline & $\begin{array}{l}\text { E. urophylla } x E \text {. } \\
\text { maidenii }\end{array}$ & & & \\
\hline \multirow[t]{4}{*}{ Xanthomonas sp. } & Eucalyptus sp. & Campo y vivero & Argentina & Gonçalves et al.2008 \\
\hline & E. grandis & & Brasil & Gonçalves et al. 2001 \\
\hline & E. grandis $x$ E. urophylla & & Cuba & Querejeta et al. 1990 \\
\hline & $\begin{array}{l}\text { E. urophylla } x E \text {. } \\
\text { maidenii }\end{array}$ & & & \\
\hline \multirow[t]{3}{*}{ Sin identificación } & E. grandis & Campo y vivero & Argentina & Alfenas et al. 2001 \\
\hline & E. saligna & & Brasil & Ferreira et al. 2001 \\
\hline & $\begin{array}{l}\text { E. urophylla } x E \text {. } \\
\text { maidenii }\end{array}$ & & Uruguay & \\
\hline
\end{tabular}


no) Mergaert et al. con esta enfermedad (Coutinho et al. 2002) al igual que en Uruguay (FAO 2006).

Los síntomas producidos por estos patógenos son diversos. En Brasil las lesiones fueron descriptas como manchas foliares amarronadas de forma angular, resecas, con perforaciones en el limbo, necrosis en la porción superior del limbo y lesiones a ambos lados de la nervadura principal, también se puede observar manchas en pecíolo y tallos jóvenes (Gonçalves et al. 2001, 2008, Neves 2007, Alfenas et al. 2009). Los síntomas evolucionan diferencialmente según la edad de las hojas. En hojas jóvenes las manchas se presentan diminutas, superficiales y con aspecto seco, mientras que en hojas completamente expandidas estas manchas son grandes con bordes irregulares y distribuidos en todo el limbo. Con el tiempo las lesiones se fusionan, conduciendo a la caída prematura de las hojas provocando defoliación (Neves 2007, Gonçalves et al. 2008, Alfenas et al. 2009) (figura 1). En Sudáfrica y Uruguay se han descrito síntomas que incluyen hojas con aspecto reseco, concentrados principalmente sobre nervadura principal y pecíolo (Coutinho et al. 2002). En Argentina y Paraguay, Ferreira et al. (2001) describieron manchas bacterianas como lesiones angulares dispersas en todo el limbo, mayormente concentradas en los bordes de las hojas y próximo a la nervadura principal.
Epidemiología. Ferreira et al. (2001) asociaron la ocurrencia de infecciones bacterianas con tormentas fuertes con ocurrencia de granizo y vientos mayores a $90 \mathrm{~km} \mathrm{~h}^{-1}$. Neves (2007) concluyó que para la infección de $X$. axonopodis es necesaria la presencia de una lámina de agua en la superficie foliar para que permita el movimiento de la misma hacia las aperturas naturales o heridas de la planta y así ingresar a los tejidos de la misma. En este sentido, Silva (2007) menciona que la mayor severidad de la enfermedad se observa en vivero, donde la humedad relativa de ambiente es alta y la presencia de agua libre en la superficie de las hojas ocurre con frecuencia debido al riego.

La temperatura óptima para el desarrollo de la enfermedad se encuentra entre 26 y $30^{\circ} \mathrm{C}$, observándose un aumento de la severidad a mayor temperatura (Neves 2007). Coincidentemente, Alfenas et al. (2009) observaron que la mayor incidencia de bacteriosis a campo, ocurre en los meses del año más cálidos, de octubre a abril, para las condiciones de Brasil.

El período de incubación para $X$. axonopodis es de aproximadamente 20 días, observándose defoliación 30 días post-inoculación. A su vez, la susceptibilidad de las hojas aumenta con la edad de las mismas, obteniendo una mayor severidad de la enfermedad en las hojas más viejas (Neves 2007).

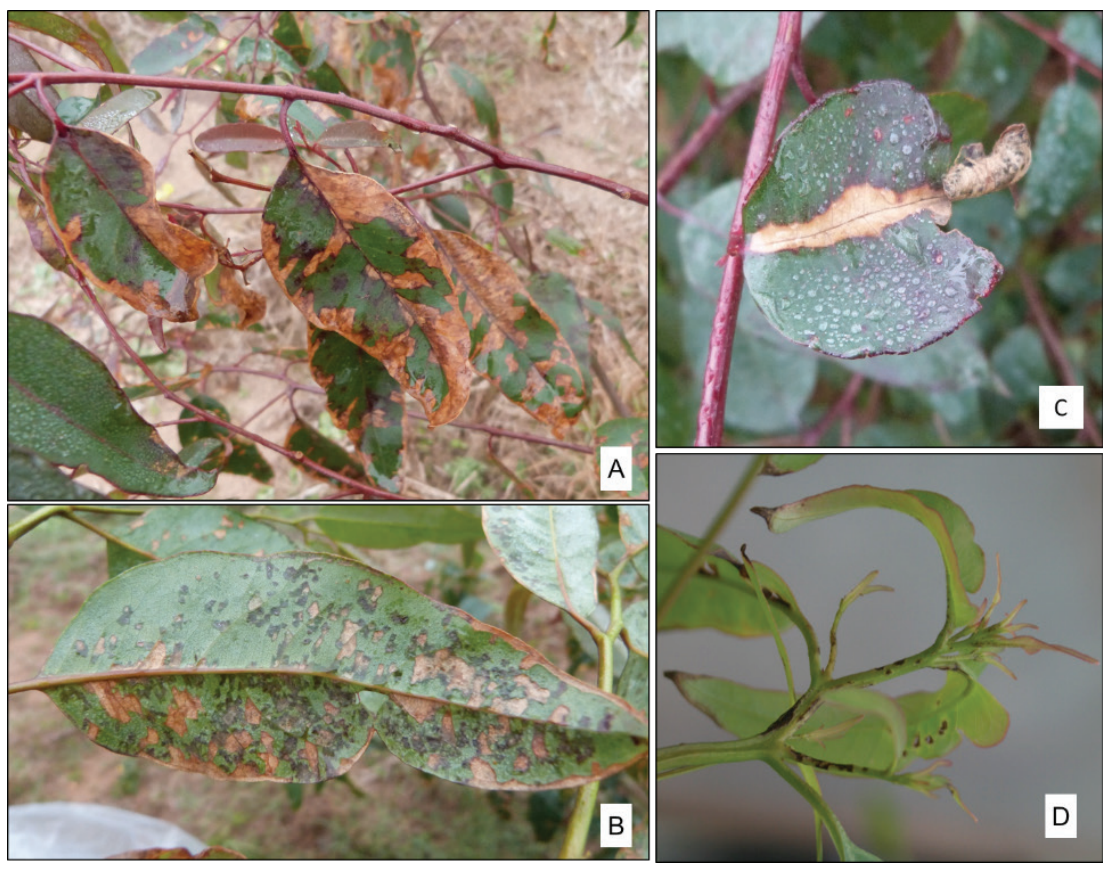

Figura 1. Manchas foliares bacterianas asociadas a X. axonopodis en Eucalyptus grandis ex Maiden en Uruguay. A) Manchas de forma irregular, distribuidas en todo el haz de la hoja, pudiendo concentrarse en los bordes de la misma. B) En el envés de la hoja se observa manchas de aspecto acuoso que no se observan en el haz. C) Manchas concentradas en la nervadura principal, pudiendo deformar la hoja. D) Manchas en pecíolo y tallos jóvenes observado en algunas ocasiones.

Bacterial leaf spot associated with X. axonopodis on Eucalyptus grandis Hill ex Maiden in Uruguay A) Leaf spots mainly irregularly distributed around the upper surface of the leaf and concentrated on the edges of the leaf, B) On the lower leaf surface watery spots are observed; they are not observed in the upper side of the blade, C) Leaf blotch on the main ridge that can deform the sheet, D) Bacterial spots on the petiole and young stems. 
Distribución geográfica y rango de hospederos. Esta enfermedad ha sido reportada con una amplia distribución geográfica regional (Argentina, Brasil y Uruguay) y el Caribe (Cuba). Afecta a un amplio rango de hospederos del género Eucalyptus (cuadro 1), y a especies ornamentales como Hibiscus elatus Swarts, Swietenia macrophylla King y Eugenia psiloclada Urb. (Querejeta et al. 1990).

Daños. La enfermedad causada por $X$. axonopodis es actualmente una de las más importantes en Eucalyptus spp., tanto en condiciones de vivero como de campo, pudiendo provocar daños significativos en materiales genéticos muy susceptibles, cuando ocurren condiciones favorables para la infección (Gonçalves 2003). Los principales daños de esta enfermedad se deben a la disminución del área foliar fotosintéticamente activa, por necrosis de tejido y defoliación, lo que lleva a la reducción del crecimiento de las plantas (Alfenas et al. 2009). La estimación del daño resulta complejo, ya que es difícil mantener un árbol libre de enfermedad, debido a los productos químicos registrados para el control bacteriano presentan acción preventiva, poca residualidad, se lixivian con la lluvia y se debe aplicar con alta frecuencia (Palladino et al. 2013).

Control de la enfermedad. La principal medida de control de la enfermedad es el uso de germoplasma resistente. Se han observado diferencias en la susceptibilidad de clones frente a manchas foliares bacterianas, detectándose diferencias en cuanto a la intensidad de la enfermedad entre distintos genotipos (Ferreira et al. 2001, Gonçalves 2003, Alfenas et al. 2009). De esta forma la resistencia genética constituye una valiosa herramienta para desarrollar programas de mejoramiento genético.

Alternativas de manejo tales como la eliminación de plantas o partes de plantas enfermas, el uso de riego por goteo, propagación de clones susceptibles en épocas desfavorables a la infección, y la utilización de materiales de propagación y herramientas libre de patógeno pueden disminuir el nivel de enfermedad, principalmente en condiciones de vivero. Entre las medidas más eficientes se encuentra evitar el humedecimiento excesivo del follaje, lo cual como se mencionó anteriormente, es crucial para el desarrollo de la enfermedad (Silva 2007).

Otra alternativa de manejo en vivero es el ajuste de la fertilización. Silva (2007) demostró que la aplicación con cloruro de potasio $(\mathrm{KCl})$ en plantines clonales de Eucalyptus globulus Labill. redujo la severidad de bacteriosis hasta en un $87 \%$ en un clon susceptible ( $53 \%$ vs. $7 \%$ de severidad), pero menciona que aumentó la incidencia de Botritys cinerea Pers. Esta reducción de bacteriosis podría explicarse por la reducción de la relación nitrógeno/potasio, y por un aumento en el tenor de azucares en el tejido foliar.

Si bien no existe hasta el momento un manejo químico efectivo de la enfermedad, y no hay ningún agroquímico registrado para su control (Alfenas et al. 2009), recientemente se ha generado información respecto al potencial del control biológico, mediante la utilización de Rizobacterias para el biocontrol de $X$. axonopodis, aunque restan estudios para su uso a nivel de producción (Marcolin et al. 2015).

\section{TIZÓN APICAL BACTERIANO}

Etiología y sintomatología. Esta enfermedad fue descripta por primera vez en eucalipto en 1974, donde se identificó a Xanthomonas campestris pv. eucalypti (Truman) Dye como el agente causal del tizón apical bacteriano afectando a Corymbia citriodora (Hook) Hill et Johnson. Los síntomas fueron descritos como muerte de las zonas distales de las ramas, que avanza hacia toda la rama, muriendo las hojas, y provocando la caída de las mismas. En epidemias severas, los árboles quedaban completamente defoliados (Truman 1974).

$\mathrm{Al}$ igual que las manchas foliares estudios posteriores han incrementado la lista de agentes causales y se ha complementado la descripción de los síntomas de esta enfermedad (cuadro 2). En Sudáfrica se identificó a Pantoea ananatis causando síntomas similares a los descritos para $X$. campestris pv. eucalypti por Truman (1974) (Coutinho et al. 2002) y más recientemente en el año 2014 a Xanthomonas vasicola Vauterin (Coutinho et al. 2014). En Argentina y Brasil, se ha identificado a Erwinia psidii como agente causal del tizón apical bacteriano (Arriel et al. 2014, Coutinho et al. 2011). En Uruguay se confirmó a E. psidii y P. ananatis como causales de esta enfermedad en eucalipto (FAO 2006, Coutinho et al. 2011). Además, en Uruguay se reportó a Enterobacter cowanii Inoue, especie aislada junto a $P$. ananatis a partir de síntomas de tizón bacteriano en Eucalyptus grandis. Se especula que E. cowanii no sea un patógeno primario, sino que se comporte como endófito y que en condiciones ambientales favorables para la enfermedad contribuya con ella (Brady et al. 2009a). Por último, Brady et al. (2009b) identificaron tres especies nuevas, cercanamente emparentadas con $P$. ananatis, que provocan la misma sintomatología de tizón apical bacteriano en eucalipto: P. eucalypti Brady, $P$. vagans Brady y $P$. deleyi Brady (cuadro 2).

El inicio de la enfermedad se da en las hojas donde se observan pequeñas manchas, que a menudo se unen para formar lesiones más grandes localizadas principalmente sobre la nervadura principal. Esta necrosis se continúa hacia los pecíolos, provocando la abscisión prematura de las hojas y luego se continúa hasta los tallos. Con el avance de la enfermedad, los árboles quedan con los ápices de crecimiento con apariencia de quemados, dando origen al nombre vulgar de la enfermedad "tizón apical" por su semejanza a la madera quemada. En algunos casos además puede observarse un levantamiento de la corteza a modo de ampollas, tanto en hojas como en tallos tiernos, que al lisarse exudan un líquido turbio, que corresponde a la zooglea bacteriana (Coutinho et al. 2002). En especies de Eucalyptus, híbridos y clones altamente susceptibles, se 
Cuadro 2. Rango de hospederos, etapa de producción y país para cada especie bacteriana asociada al tizón apical bacteriano en Eucalyptus spp.

Host range, production stage and country where each bacterial species associated with bacterial die-back or shoot blight in Eucalyptus spp. has been reported.

\begin{tabular}{|c|c|c|c|c|}
\hline Agente causal & Hospedero & Etapa de producción & País & Referencias \\
\hline Enterobacter cowanii & E. grandis & Campo & Uruguay & Brady et al. 2009a \\
\hline \multirow[t]{5}{*}{ Erwinia psidii } & E. dunnii & Campo & Argentina & Arriel et al. 2014 \\
\hline & E. globulus & & Brasil & Coutinho et al. 2011 \\
\hline & E. grandis & & Uruguay & \\
\hline & E. saligna & & & \\
\hline & $\begin{array}{l}\text { E. urophylla } x E \text {. } \\
\text { grandis }\end{array}$ & & & \\
\hline \multirow[t]{4}{*}{ Pantoea ananatis } & E. globulus & Campo y vivero & Argentina & Coutinho et al. 2014 \\
\hline & E. grandis & & Brasil & Coutinho et al. 2002 \\
\hline & E. grandis $\times E$. nitens & & Sudáfrica & FAO 2006 \\
\hline & & & Uruguay & \\
\hline P. eucalypti & Eucalyptus sp. & Campo & Uruguay & Brady et al. 2009b \\
\hline P. deleyi & Eucalyptus sp. & Campo & Uganda & Brady et al. 2009b \\
\hline \multirow[t]{3}{*}{ P. vagans } & Eucalyptus sp. & Campo & Argentina & Brady et al. 2009b \\
\hline & & & Uganda & \\
\hline & & & Uruguay & \\
\hline Xanthomonas campestris pv. eucalypti & Corymbia citridora & Campo & Australia & Truman 1974 \\
\hline$X$. vasicola & E. grandis & Campo & Sudáfrica & Coutinho et al. 2014 \\
\hline
\end{tabular}

observa una combinación de síntomas de muerte regresiva y manchas, mientras que los que se muestran más tolerantes únicamente se observan manchas foliares (Coutinho et al. 2002) (figura 2).

La presencia de Xanthomonas vasicola como agente causal de tizón bacteriano en Sudáfrica es considerado como un salto de hospedero desde una monocotiledónea como lo es la caña de azúcar, a una especie dicotiledónea como lo es el eucalipto. Los síntomas iniciales son lesiones acuosas en las hojas, a lo largo de la nervadura principal, las cuales se convierten rápidamente en necróticas, y se fusionan formando lesiones mayores. La evolución de la enfermedad provoca también la muerte regresiva de la rama (Coutinho et al. 2014).

Epidemiología. Pantoea ananatis ha sido observada afectando árboles de 3 a $7 \mathrm{~m}$ de altura, principalmente cuando ocurre el cambio de follaje juvenil a hoja adulta (Coutinho et al. 2002). Este patógeno se dispersa favorecido por el salpicado de gotas de lluvia durante tormentas y/o por insectos que pueden en forma pasiva diseminar la enfermedad (Coutinho et al. 2002, 2014, FAO 2006), encontrándose frecuentemente asociada al psílido Ctenarytaina sp. (FAO 2006). Otros autores mencionan que no hay una clara asociación de $P$. ananatis con insectos vectores. A su vez las infecciones por esta bacteria se ven favorecidas por temperaturas entre 20 y $25^{\circ} \mathrm{C}$, y una alta humedad relativa (Coutinho et al. 2002, 2014). Por su parte, Xanthomonas vasicola también se disemina por salpicadura de lluvia, se transporta por medio de los insectos, la manipulación y traslado de herramientas por el hombre. La infección ocurre en las mismas condiciones ambientales que $P$. ananatis (Coutinho et al. 2014).

Erwinia psidii se la ha observado principalmente en plantaciones jóvenes, de 6 a 24 meses de edad (Coutinho et al. 2011). Existen algunos estudios epidemiológicos de E. psidii en Psidium guajava L., que demuestran la capacidad de la bacteria de sobrevivir en restos de vegetales infectados, en el suelo y/o asociada a hospederos secundarios. Esta bacteria puede ingresar a la planta a través de aberturas naturales y/o por heridas causadas por herramientas, viento, o granizo. Durante períodos secos y fríos la incidencia de la enfermedad disminuye, favoreciéndose con alta temperatura y humedad relativa. A su vez, existen evidencias de que los niveles de infección aumentan ante un exceso de fertilización nitrogenada (Junqueira 2000). 


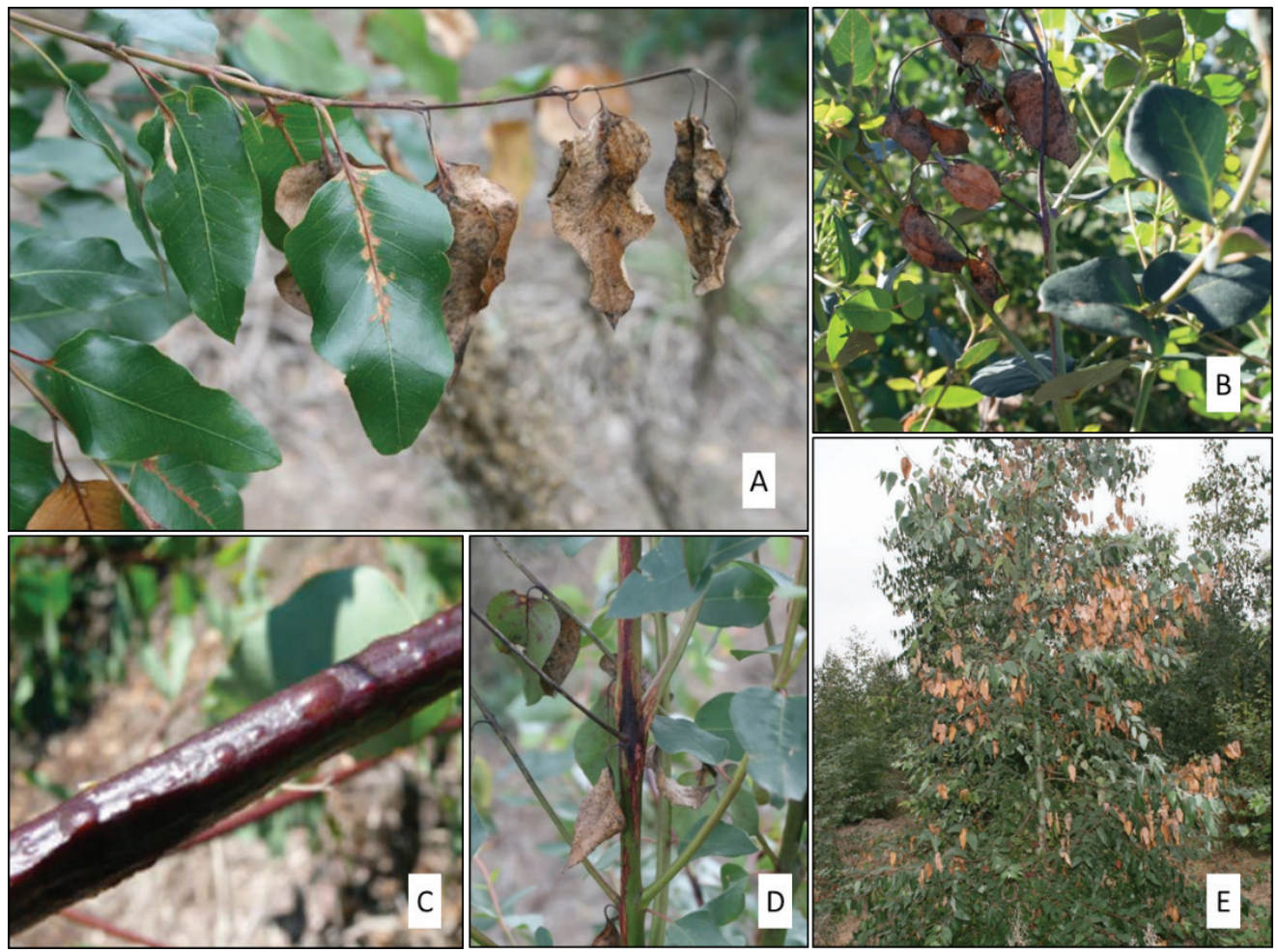

Figura 2. Tizón apical bacteriano en Eucalyptus dunnii asociado a Erwinia psidii en Uruguay. A) Tizón apical en brote lateral con manchas en las hojas localizadas sobre la nervadura principal. B) Muerte descendente desde el ápice hacia el tallo. C) Ampollas en tallo suculento conteniendo zooglea bacteriana. D) Cancro producido por tizón en tallo. E) Árbol con múltiples ápices afectados luego de un ataque severo de tizón.

Shoot blight associated with Erwinia psidii on Eucalyptus dunnii in Uruguay. A) Shoot blight with leaf spots located on the midrib, B) Young shoot dieback from top to bottom, C) Bacteria blisters on young stem, D) Canker driven from stem blight, and E) Tree showing multiple infected leaders after a severe blight attack.

Distribución geográfica y rango de hospederos. La enfermedad ha sido reportada en países de América del sur, como ser Argentina, Brasil y Uruguay; África y Australia, afectando a un amplio rango de especies de eucaliptos (cuadro 2). No solo afecta a los géneros Eucalyptus y Corymbia dentro de la familia Mirtaceae sino que también afecta al género Psidium (i.e. Psidium guajava). La detección de E. psidii en Eucalyptus spp. es considerada un salto de hospedero desde el monte nativo, específicamente desde Psidium guajava, hacia las plantaciones comerciales de eucalipto (Coutinho et al. 2011).

Daños. Pantoea ananatis puede provocar graves pérdidas económicas. En infecciones reiteradas, el ápice principal pierde la dominancia, generando brotes múltiples, deformaciones del fuste, y problemas de arquitectura de copa, lo que ocasiona pérdidas de crecimiento en altura. En ataques severos puede ocasionar la muerte de la planta (Coutinho et al. 2002, FAO 2006).

Para el caso de E. psidii, se han observado incidencias de casi el $100 \%$ de las plantas en determinados sitios y épocas del año, resultando en la pérdida de la dominancia apical y reducción del crecimiento (Coutinho et al. 2011, Arriel et al. 2014). Sin embargo, en la mayoría de los casos, la recuperación de los árboles es relativamente rápida, debido al rápido crecimiento y al desarrollo de yemas axilares que prontamente retoman la dominancia apical (Coutinho et al. 2011).

Control de la enfermedad. Alfenas et al. (2009) mencionan a la resistencia genética como la principal medida de manejo de esta enfermedad, debido a la variabilidad en la intensidad de la enfermedad observada entre distintos germoplasmas de Eucalyptus spp. Para el caso del control de Erwinia psidii en Psidium guajava, el manejo de la enfermedad se realiza preventivamente, destruyendo en vivero los restos de poda de los brotes infectados, utilizando plantas sanas, y evitando el uso de semillas, estacas o mudas provenientes de lugares donde ya se ha observado la enfermedad. Además se utilizan pulverizaciones preventivas con productos cúpricos previniendo infecciones. Otra alternativa de manejo es evitar el uso excesivo de fertilizantes nitrogenados, porque estos favorecen las nuevas brotaciones y facilitan la penetración de este patógeno (Junqueira 2000). 


\section{MARCHITAMIENTO VASCULAR CAUSADO POR BACTERIAS}

Etiología y sintomatología. El marchitamiento vascular bacteriano fue reportado por primera vez en Brasil en 1983, asociado a Ralstonia solanacearum (Smith) Yabuuchi (Sudo et al. 1983). Esta especie es considerada una de las bacterias fitopatógenas más importantes del mundo debido a los grandes perjuicios económicos que causa, la dificultad de control, su amplia distribución geográfica, y al amplio rango de hospederos que posee (Hayward 2000). Esta enfermedad ha sido recientemente asociada también a Erwinia psidii (Arriel et al. 2014), causante del tizón apical bacteriano (Coutinho et al. 2011). Este patógeno provoca síntomas muy similares a $R$. solanacearum, lo que resulta imposible diferenciar a campo (Arriel et al. 2014).

El síntoma típico de la enfermedad es un marchitamiento generalizado de la planta, que comienza desde arriba hacia abajo (figura 3). Las hojas presentan lesiones medianas a grandes, irregulares, oscuras, pudiéndose tornar a marrón claras en los bordes de las hojas. Esta enfermedad puede provocar coloración oscura en la madera. Las plantas más propensas a la enfermedad son aquellas con sistema radicular malformado, con heridas en el tronco o base del tallo. La enfermedad ha sido observada tanto en vivero como en el campo (Coutinho et al. 2000, Alfenas et al. 2006, 2009, Mafia et al. 2012).
Epidemiología. Ralstonia solanacearum es capaz de sobrevivir en el suelo o en residuos de la rotación previa. Pese a esto, no se ha comprobado un claro efecto de la rotación sobre la ocurrencia de la enfermedad (Mafia et al. 2012), probablemente debido a la presencia de inóculo aún en situaciones sin precedentes del cultivo. Esta bacteria puede diseminarse a largas distancias por medio de material propagativo infectado, o diseminarse a cortas distancias por herramientas e insectos (Mafia et al. 2012). La infección ocurre a través de heridas en el sistema radicular, siendo favorecida por alta temperatura y humedad en el suelo. Por esta razón, la mayor intensidad de la enfermedad ocurre en veranos lluviosos (Alfenas et al. 2009).

La ocurrencia de altas temperaturas sumadas a déficit hídrico en el suelo, puede resultar en escaldado en el cuello de la planta. Esto constituye una posible vía de entrada para las bacterias que, si cambian las condiciones ambientales y se da la presencia de agua libre en el suelo, pueden infectar la planta (Alfenas et al. 2006). Situación similar se genera en el microclima de viveros clonales, donde se alternan períodos de altas temperaturas con riegos frecuentes, lo que es ideal para la supervivencia y multiplicación de las bacterias, desarrollándose así varios ciclos de la enfermedad (Mafia et al. 2012).

La epidemiología de la enfermedad causada por $R$. solanacearum se ha estudiado en condiciones controladas mediante inoculación artificial. Los síntomas de la
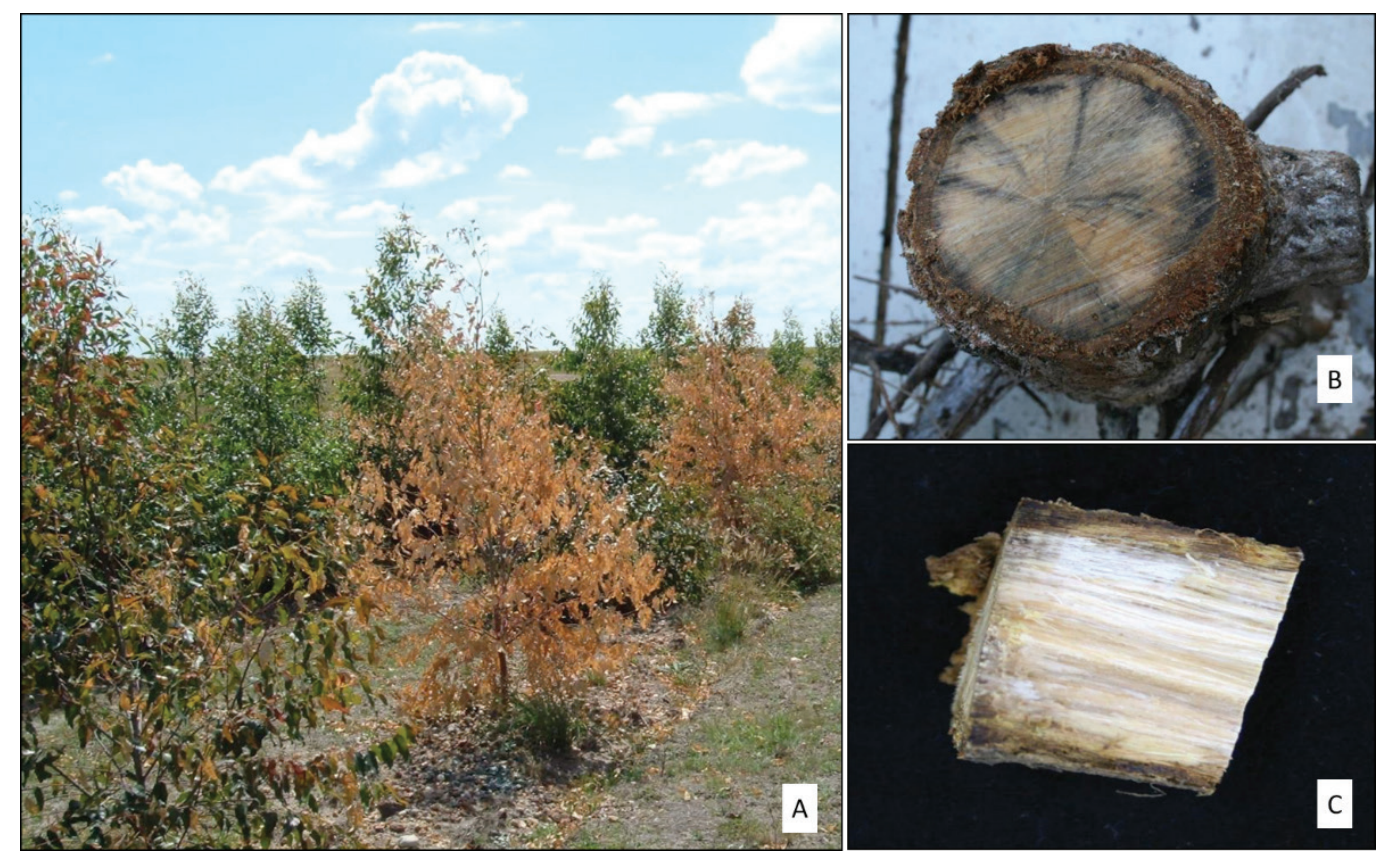

Figura 3. Marchitamiento vascular bacteriano observado en Eucalyptus grandis en Uruguay. A) Marchitamiento vascular generalizado. B) Corte transversal del fuste. C) Corte longitudinal del fuste cercano la base del árbol donde se observa coloración oscura producto de la colonización bacteriana.

Bacterial vascular wilt on Eucalyptus grandis in Uruguay. A) Generalized vascular wilt, B) Transversal and C) Longitudinal cross section of the main stem near the base of the tree showing discoloration as a result of bacterial colonization. 
enfermedad fueron reproducidos a los tres días de la inoculación, observándose muerte de plantas a los 10 días post-inoculación (Coutinho et al. 2000). En condiciones de campo no hay precedentes de inoculación artificial, y es difícil estimar el período de incubación cuando la inoculación ocurre naturalmente. Sin embargo, se ha observado que los síntomas pueden aparecer tan pronto como a los tres o cuatro meses después de la plantación, pudiendo provocar la muerte de los árboles a las dos o tres semanas posteriores a la aparición de los primeros síntomas. En otros casos la muerte puede demorar hasta seis meses post-infección (Coutinho et al. 2000).

Por el contrario, es limitada la información respecto a E. psidii. Esta especie fue recientemente identificada como agente causal del marchitamiento, habiendo limitantes de información respecto a su epidemiología. Arriel et al. (2014) mencionan que este patógeno provoca marchitamiento en plantas de dos a tres meses de edad.

Distribución geográfica y rango de hospederos. La marchitez bacteriana ocasionada por $R$. solanacearum presenta una amplia distribución geográfica, es generalizada en todas las regiones templadas, tropicales, subtropicales y cálidas del mundo (Mafia et al. 2012) (cuadro 3).

Ralstonia solanacearum presenta un amplio rango de hospederos, siendo capaz de causar enfermedad en más de 200 especies de plantas, englobando aproximadamente 50 familias botánicas (Hayward 2000, Mafia et al. 2012). Dentro de las mirtáceas, afecta a una gran diversidad de especies, las cuales presentan diferente susceptibilidad (cuadro 3). En cambio, Erwinia psidii ha sido observada provocando marchitamiento vascular únicamente en híbridos de Eucalyptus urophylla Blake x Eucalyptus grandis y Eucalyptus saligna Sm. (Arriel et al. 2014).

En Uruguay, la enfermedad ha sido observada en plantaciones de Eucalyptus spp., sin embargo, hasta la fecha no hay antecedentes de estudios que hayan identificado la etiología de dicha enfermedad. Los síntomas observados a campo son típicos de esta enfermedad (figura 3), y sin dudas que futuros estudios deberán confirmar la etiología de esta enfermedad en dicho país.

Daños. El marchitamiento vascular bacteriano es una enfermedad de gran importancia económica (Mafia et al. 2012), causando enormes pérdidas en viveros de eucalipto (Alfenas et al. 2006, 2009) у a campo (Old et al. 2003). Dentro de estas pérdidas está la disminución en la producción de miniestacas y en los índices de enraizamiento obtenidos en vivero (Alfenas et al. 2006), y un alto porcentaje de mortandad en plantaciones comerciales de Eucalyptus urophylla y Eucalyptus pellita Muell. (Old et al. 2003).

Control de la enfermedad. El marchitamiento bacteriano por la naturaleza sistémica de las infecciones dificulta su control (Mafia et al. 2012). Una vez establecida la enfermedad en el campo, el control del patógeno es difícil. En condiciones de campo se enfatiza en la correcta elección del sitio forestal, evitando suelos con limitantes físicas para el crecimiento radicular, la utilización de plantines con buen pan radicular y excelente arquitectura de raíz,

Cuadro 3. Rango de hospederos, etapa de producción y país para cada especie bacteriana asociada al marchitamiento vascular bacteriano en Eucalyptus spp.

Host range, production stage and country where each bacterial species associated with vascular wilt in Eucalyptus spp. has been reported.

\begin{tabular}{|c|c|c|c|c|}
\hline Agente causal & Hospedero & Etapa de producción & País & Referencias \\
\hline \multirow[t]{2}{*}{ Erwinia psidii } & E. saligna & Campo & Brasil & Arriel et al. 2014 \\
\hline & E. urophylla $\times$ E. grandis & & & \\
\hline \multirow[t]{12}{*}{ Ralstonia solanacearum $(*)$} & C. citriodora & Campo y vivero & Australia & Alfenas et al. 2009 \\
\hline & E. camaldulensis & & Brasil & Askiew y Tevorow 1994 \\
\hline & E. grandis & & China & Ciesla et al. 1996 \\
\hline & & & Venezuela & \\
\hline & E. grandis $x$ E. urophylla & & Indonesia & Coutinho et al. 2000 \\
\hline & Eucalyptus sp. & & Paraguay & Santiago et al. 2014 \\
\hline & E.pellita & & Sudáfrica & Roux et al. 2001 \\
\hline & E. propinqua & & Taiwán & Sudo et al. 1983 \\
\hline & E. saligna & & Uganda & Wu y Liang $1988 \mathrm{a}$ \\
\hline & E. tereticornis & & Vietnam & Wang 1992 \\
\hline & E. urophylla & & & \\
\hline & E. urophylla $x$ E. grandis & & & \\
\hline
\end{tabular}

(*) Sólo se lista la información respecto a eucalipto, debido a que esta especie presenta un amplio rango de hospederos que incluye a numerosos cultivos. 
plantación de calidad, y cuidando la correcta deposición del pan radicular en el pozo de plantación, en definitiva, todo manejo que minimice la generación de heridas que permitan el ingreso de las bacterias. De igual modo, en el vivero, se recomienda el control integrado, basado en varias medidas preventivas, como ser el uso de plantines sanos, agua de riego sana, utilización de herramientas libre de inóculo (Alfenas et al. 2006, 2009).

El principal control de esta enfermedad es la resistencia genética, ya que se han observado diferencias en la susceptibilidad del germoplasma frente a esta enfermedad (Coutinho et al. 2000). Esta variabilidad observada a campo, debe ser complementada con pruebas de inoculación artificial para poder dilucidar si el mejor comportamiento de un germoplasma se debe a un escape o a resistencia a la enfermedad (Wu y Liang 1988, Alfenas et al. 2006, 2009). Mafia et al. (2014) mencionan que Eucalyptus tereticornis $\mathrm{Sm}$. es una de las especies con mejor comportamiento frente a la enfermedad, en relación al resto de las especies incluidas en el estudio: Eucalyptus camaldulensis Dehnh., E. dunnii, E. globulus, E. grandis y E. saligna.

Otra alternativa posible para el control de esta enfermedad es el control biológico, Ran et al. (2005) mencionan el uso de cepas específicas de Pseudomonas fluorescentes (rizobacterias) para el control del marchitamiento en eucalipto en plantines en China.

\section{CONSIDERACIONES FINALES}

Las enfermedades de origen bacteriano en eucalipto han aumentado su importancia relativa con respecto a otros agentes etiológicos, ya sea por un aumento en el número de reportes a nivel mundial, como en el daño potencial que ellas ocasionan, ya que provocan graves pérdidas económicas tanto a campo como en vivero (Alfenas et al. 2009). Dada la importancia del cultivo de eucalipto a nivel mundial, y particularmente en la región, y la escasa disponibilidad de artículos que reúnan la información disponible, se valoró fundamental ejecutar este trabajo. Esta revisión busca compilar la información disponible en la literatura internacional generada en los últimos años.

Las pérdidas que ocasionan las enfermedades bacterianas, junto con la dificultad de su control, hacen que la principal medida de control sea la resistencia genética, observándose diferencias en la susceptibilidad del germoplasma frente a las diferentes enfermedades (Coutinho et al. 2000, Gonçalves 2003, Alfenas et al. 2009, Mafia et al. 2014). Dado que los estudios de resistencia genética suelen llevar años, la medida de control más utilizada está enfocada en vivero, realizando un manejo integrado basado en varias medidas preventivas. La investigación debería enfocarse en el corto plazo en el control biológico de estas enfermedades en vivero, ya que hay evidencias de experiencias promisorias en mancha foliar (Marcolin et al. 2015) y en marchitamiento vascular (Ran et al. 2005). También la manipulación genética, como lo mencionan Naidoo et al. (2011) como posible estrategia de control de Ralstonia solanacearum, se ha convertido en un enfoque innovador poco explorado hasta la fecha.

Como se mencionó anteriormente, la mayoría de las enfermedades bacterianas en Eucalyptus spp. han sido reportadas en los últimos 15 años, y predominan los estudios sobre la etiología. La identificación del organismo causal es el primer paso en el manejo de enfermedades, pero estudios futuros deberán estar enfocados a enriquecer la escasa información sobre epidemiología y manejo. Este tipo de información no sólo permitirá minimizar las pérdidas que causan estas enfermedades en la producción forestal, sino además deberán incluir estudios que permitan limitar la diseminación de estas bacterias entre países o regiones, uno de los puntos más limitantes en la producción actual.

Otra línea de investigación que deberá ser enriquecida es la interacción biológica entre las plantaciones forestales y el monte nativo. Como se mencionó líneas arriba, hay evidencias del salto de hospedero de bacterias desde especies nativas hacia el eucalipto introducido, sin embargo, no se encontraron antecedentes que estudien el salto de estas enfermedades desde las plantaciones forestales hacia el monte nativo. Sin dudas estas limitantes de información van a ser paulatinamente levantadas en el mediano plazo dada la mayor investigación actual en estas enfermedades a nivel global.

\section{REFERENCIAS}

Alfenas AC, RC Gonçalves, JR Oliveira, IT Silva, S Oda, TF Assis. 2001. Mancha foliar e desfolha de Eucalyptus urophylla x E. maidenii, causadas por fitobacterias. Fitopatología Brasileira 26:294-294.

Alfenas AC, RG Mafia, RC Sartório, DHB Binoti, RR Silva, D Lau, CA Vanetti. 2006. Ralstonia solanacearum em viveiros clonais de eucalipto no Brasil. Fitopatologia Brasileira 31(4):357-366. DOI: 10.1590/S0100-41582006000400005.

Alfenas AC, EA Valverde, R Mafia, FT Assis. 2009. Clonagem e Doenças do Eucalipto. Viçosa, Brasil. UFV. 500 p.

Arriel A, NR Fonseca, LMS Guimarães, PS Hermenegildo, RG Mafía, N Borges Júnior, HP De Souza, AC Alfenas. 2014. Wilt and die-back of Eucalyptus spp. caused by Erwinia psidii in Brazil. Forest Pathology 44(4): 255-265. DOI: 10.1111/efp.12087.

Askiew E, PR Tevorow. 1994. Management of bacterial wilt of tobacco. In Hayward AC, GL Hartman eds. Bacterial wilt: the disease and its causative agent, Pseudomonas solanacearum. Wallingford, UK. CAB International. p. 179-198.

Brady CL, SN Venter, I Cleenwerck, K Engelbeen, P de Vos, MJ Wingfield, N Telechea, TA Coutinho. 2009a. Isolation of Enterobacter cowanii from Eucalyptus showing symptoms of bacterial blight and dieback in Uruguay. Letters in Applied Microbiology 49(4):461-465. DOI: 10.1111/j.1472765X.2009.02692.x.

Brady CL, SN Venter, I Cleenwerck, K Engelbeen, M Vancanneyt, J Swings, TA Coutinho. 2009b. Pantoea vagans sp. nov., Pantoea eucalypti sp. nov., Pantoea deleyi sp. nov. and Pantoea anthophila sp. nov. International Journal of Systematic and Evolutionary Microbiology 59(9):23392345. DOI: 10.1099/ijs.0.009241-0.

Ciesla WM, M Diekmann, CA Putter. 1996. Eucalyptus spp.: Te- 
chnical Guide-lines for the safe movement of germplasm. Rome, Italia. FAO/IPGRI. 68 p.

Coutinho TA, J Roux, KH Riedel, J Terblanche, MJ Wingfield. 2000. First report of bacterial wilt caused by Ralstonia solanacearum on eucalypts in South Africa. Forest Pathology 30(4):205-210. DOI: 10.1046/j.1439-0329.2000.00205.x.

Coutinho TA, O Preisig, J Mergaert, MC Cnockaert, KH Riedel, J Swings, MJ Wingfield. 2002. Bacterial blight and dieback of Eucalyptus species, hybrids, and clones in South Africa. Plant Disease 86(1): 20-25. DOI: 10.1094/PDIS.2002.86.1.20.

Coutinho TA, CL Brady, M Van Der Vaart, SN Venter, N Telechea, M Rolfo, C Pérez, MJ Wingfield. 2011. A new shoot and stem disease of Eucalyptus species caused by Erwinia psidii. Australasian Plant Pathology 40(1):55-60. DOI: 10.1007\%2Fs13313-010-0013-y.

Coutinho TA, L Van der Westhuizen, J Roux, FA McFarlane, SN Venter. 2014. Significant host jump of Xanthomonas vasicola from sugarcane to a Eucalyptus grandis clone in South Africa. Plant Pathology 64(3):576-581. DOI: 10.1111/ppa.12298.

FAO. 2006. Manual de campo: Plagas y enfermedades de Eucaliptos y Pinos en el Uruguay. Consultado 10 feb. 2016. Disponible en http://www.fagro.edu.uy/ forestal/cursos/proteccion/ Fao\%20Manual\%20de\%20Campo.pdf

Ferreira FA, JR Oliveira, R Romeiro. 2001. Uma bacteriose foliar em Eucalyptus grandis na Argentina e Paraguai. Fitopatologia brasileira 26: 281 (Abstract).

Gonçalves RC. 2003. Etiología da mancha bacteriana do eucalipto no Brasil. Tesis de Doctorado em Ciencias. Viçosa, Brasil. Facultade Engenharia Florestal, Universidade Federal de Viçosa. 94 p.

Gonçalves RC, AC Alfenas, JR Oliveira, IT Silva, S Oda, TF Assis, A Tonon. 2001. Mancha foliar e seca de ponteiros do eucalipto causada por fitobacterias, no Brasil e na Argentina. Fitopatología Brasileira 26:294 (Abstract).

Gonçalves RC, D Lau, JR Oliveira, LA Mafia, CM Casardo, AC Alfenas. 2008. Etiología da mancha bacteriana do eucalipto no Brasil. Tropical Plant Pathology 33(3):180-188. DOI: 10.1590/S1982-56762008000300002.

Hayward AC. 2000. Ralstonia solanacearum. In Lederberg J ed. Encyclopedia of Microbiology. San Diego, Estados Unidos. Academic Press. p. 32-42.

Junqueira NTV. 2000. Doenças e Pragas. In Manica I eds. Fruticultura Tropical 6 Goiaba. Porto Alegre, Brasil. Cinco Continentes. p. 225-270.

Marcolin G, AL Moura do Carmo, F Augusto de Oliveira Garcia. 2015. Biocontrole in vitro de mancha foliar bacteriana do eucalipto, mediado por rizobacterias. Enciclopédia Biosfera 11(21):346-354.

Mafia R, A Alfenas, RM Penchel, MA Ferreira, R Alfenas. 2012. Murcha-bacteriana: Disseminaçao do patógeno e efeitos da doença sobre a clonagem do Eucalipto. Revista Árvore 36(4):593-602.

Mafia R, A Alfenas, M Ferreira. 2014. Avaliaçao da resistência do eucalipto a murcha-bacteriana causada por Ralstonia solanacearum. Revista Árvore 38(4):649-656.

Naidoo S, J Fouché-Weich, P Law, KL Denby, Y Marco, DK Berger. 2011. A Eucalyptus bacterial wilt isolate from South
Africa is pathogenic on Arabidopsis and manipulates host defenses. Forest Pathology 41(2):101-113.

Naidoo S, C Külheim, L Zwart, R Mangwanda, CN Oates, EA Visser, FE Wilken, TB Mamni, AA Myburg. 2014. Uncovering the defense responses of Eucalyptus to pests and pathogens in the genomics age. Tree Physiology 34(9):931-943. DOI: $10.1093 /$ treephys/tpu075.

Neves DA. 2007. Condições favoráveis à mancha foliar causada por Xanthomonas axonopodis em eucalipto Tesis de Magíster em Ciencias. Viçosa, Brasil. Facultade Engenharia Florestal, Universidade Federal de Viçosa. 33 p.

Old M, MJ Wingfield, ZQ Yuan. 2003. A manual of diseases of eucalypts in South-East Asia. Canberra, Australia. Center for International Forestry Research. 98 p.

Palladino MC, G Pérez, R Alonso, CA Pérez. 2013. Enfermedades bacterianas en Eucalipto: estado del conocimiento a nivel nacional. In Balmelli G, S Simeto, G Martínez, D Gómez eds. VI Jornada técnica de protección forestal. Montevideo, Uruguay. INIA. Serie Técnica 213. p. 53-63.

Pérez CA, MJ Wingfield, B Slippers, NA Altier, RA Blanchette. 2010. Endophytic and canker-associated Botryosphaeriaceae occurring on non-native Eucalyptus and native Myrtaceae tres in Uruguay. Fungal Diversity 41(1):53-69. DOI: 10.1007\%2Fs13225-009-0014-8.

Pomella AWV, Romeiro RS, Ferreira FA, Oliveira JR. 1995. Lesoes foliares em viveiro de Eucalipto incitadas por una espécie fluorescente de Pseudomonas. Fitopatologia Brasileira 20: 374 (Abstract).

Querejeta M, M Cordovez, A Brooks, I Moreno, B Piedra, M Hernandez. 1990. Mancha bacteriana en especies forestales causada por Xanthomonas sp. Protección de Plantas 13: 52-59.

Ran LS, CY Liu, GJ Wu, LC Van Loon, PAHM Bakker. 2005. Suppression of bacterial wilt in Eucalyptus urophylla by fluorescente Pseudomonas spp. in China. Biological Control 32(1):111-120. DOI: 10.1016/j.biocontrol.2004.08.007.

Roux J, D Coutinho, D Mujini Byabachaija, MJ Wingfield. 2001. Diseases of plantation Eucalyptus in Uganda. South African Journal of Science 97:16-18.

Santiago TR, C Grabowski, ESG Mizubuti. 2014. First report of bacterial wilt caused by Ralstonia solanacearum on $\mathrm{Eu}$ calyptus sp. in Paraguay. New Disease Reports 29: 2.

Silva A. 2007. Histopatología e influência de nutrientes na itensidade da bacteriose foliar do eucalipto causada por Xanthomonas axonopodis. Tesis de Doctorado em Ciencias. Viçosa, Brasil. Facultade Ciencias Florestales. Universidade Federal de Viçosa. 71 p.

Sudo S, GHN Oliveira, AC Pereira. 1983. Eucalipto (Eucalyptus sp.) e bracatinga (Mimosa scabrella Benth), novos hospedeiros de Pseudomonas solanacearum E.F. Smith. Fitopatologia Brasileira 8:631 (Abstract).

Truman R. 1974. Die-back of Eucalyptus citriodora caused by Xanthomonas eucalypti sp. nov. Phytopathology 64:143-144.

Wang WY. 1992. Survey of Eucalyptus diseases in Taiwan. Bulletin Taiwan Forest Research Institute 7(2):179-188.

Wu QP, ZC Liang. 1988. Identification and pathogenic tests of the causal organism of the bacterial wilt of Eucalyptus. Journal South China Agriculture University 9:59-67. 